\title{
PEMBERDAYAAN MASYARAKAT NON PRODUKTIF MELALUI KETERAMPILAN PEMBUATAN TAWAS DARI LIMBAH KALENG BEKAS MINUMAN
}

\section{EMPOWERMENT OF NON-PRODUCTIVE SOCIETY THROUGH SKILL MAKING OFF ALUM FROM WASTE CAN USED DRINKS}

\author{
A Iryani ${ }^{1 a}$, Sutanto ${ }^{1}$, dan M Fathurrachman ${ }^{1}$ \\ 1Program Studi Kimia, Fakultas Matematika dan Ilmu Pengetahuan Alam, Universitas Pakuan, \\ Jalan Pakuan PO Box 452 Bogor 16143 Jawa Barat Indonesia \\ a Korespondensi: Ani Iryani, Email: ani_iryani62@yahoo.co.id
}

(Diterima: 20-08-2017; Ditelaah: 20-08-2017; Disetujui: 22-10-2017)

\begin{abstract}
Leuwiliang Village, Leuwiliang District, Bogor Regency, is a village that has a fairly dense population with diverse livelihoods. Village Government information is known as $25 \%$ of the population has not had a job, so classified as a non-productive society with a very limited educational background and skills. The people of this group are right as partners of abdimas to be given an advanced skills in order to be independent. In this abdimas given the skill to make alum from waste used drink cans. The existing hope can transform into a working society and become a productive society. Instead it can improve the economic prosperity of the village. Abdimas this time was chosen from RW 10 residents of Leuwiliang village with potential both men and women. In addition, also selected the Foundation of Islamic Education Saefulloh Assa'diyyah (YAPISA) which can provide a means of producing alum from the raw materials used tin cans. Implementation of this program is done through training and demonstration skill of alum making from raw materials of beverage cans for household scale until finished product with good alum quality, this training had be done 4 time in July and August 2017. The results are very satisfying, the community was very enthusiast, they able to make alum products well and able to demonstrate how to use alum products for purification of turbid water.
\end{abstract}

Keywords: abdimas, alum, KOH, waste used tin cans.

\begin{abstract}
ABSTRAK
Desa Leuwiliang Kecamatan Leuwiliang Kabupaten Bogor, adalah desa yang memiliki jumlah penduduk cukup padat dengan mata pencaharian yang beragam. Dari informasi pemerintah Desa Leuwiliang diketahui sebanyak $25 \%$ penduduk belum memiliki pekerjaan, sehingga tergolong sebagai masyarakat non-produktif dengan latar belakang pendidikan dan keterampilan yang sangat terbatas. Masyarakat kelompok ini tepat sebagai mitra Abdimas untuk diberikan keterampilan lanjut agar bisa mandiri. Pada abdimas ini diberikan keterampilan membuat tawas dari limbah kaleng bekas minuman. Harapan yang ada dapat mengubah menjadi masyarakat berkarya serta menjadi masyarakat yang produktif. Alih-alih dapat meningkatkan kesejahteraan ekonomi di desa tersebut. Abdimas kali ini dipilih dari warga RW 10 Desa Leuwiliang yang potensial baik laki-laki maupun perempuan. Selain itu dipilih juga Yayasan Pendidikan Islam Saefulloh Assa'diyyah (YAPISA) yang dapat menyediakan sarana berupa tempat memproduksi tawas dari bahan baku berupa kaleng bekas. Pelaksanaan program ini dilakukan melalui pelatihan dan demontrasi keterampilan pembuatan tawas dari bahan baku kaleng bekas minuman untuk skala industri rumah tangga sampai dihasilkan produk jadi dengan kualitas tawas yang baik. Pelatihan ini dilaksanakan 4
\end{abstract}


kali pada bulan Juli dan Agustus 2017. Hasil yang didapat sangat memuaskan, masyarakat sangat antusias mengikuti tahap demi tahap pelatihan dan mampu membuat produk tawas dengan baik dan mampu memperagakan bagaimana menggunakan produk tawasnya untuk menjernihkan air keruh.

Kata kunci: abdimas, $\mathrm{KOH}$, limbah kaleng bekas minuman, tawas.

Iryani A, Sutanto, dan M Fathurrachman. 2017. Pemberdayaan masyarakat non produktif melalui keterampilan pembuatan tawas dari limbah kaleng bekas minuman. Qardhul Hasan: Media Pengabdian kepada Masyarakat 3(2): 99 - 106.

\section{PENDAHULUAN}

Wilayah Kecamatan Leuwiliang Kabupaten Bogor, utamanya desa Leuwiliang yang berjarak $34 \mathrm{~km}$ sebelah barat Kota Bogor, wilayah ini merupakan kawasan pedesaan dengan jumlah penduduk yang cukup padat dan perkembangannya relatif cepat. Hal ini membuat perekonomian di Desa Leuwiliang bergerak sangat lambat. Lemahnya perekonomian masyarakat tercermin pada buku laporan kinerja Kepala Desa Leuwiliang tahun 2015 yaitu 25\% belum memiliki pekerjaan, $6,8 \%$ petani, buruh tani, dan buruh harian lepas, 30,5\% pedagang dan wirausaha, 2,4\% sebagai Pegawai Negeri Sipil dan TNI/POLRI. Data ini kemungkinan terkait karena latar belakang pendidikan sangat rendah, yakni : tamat SD sebanyak $48,5 \%$, tamat SMP sebanyak $21,9 \%$, tamat SMA sebanyak $25,8 \%$, dan hanya $3,8 \%$ saja yang berhasil tamat diploma dan sarjana.

Besarnya angka profesi sebagai pedagang dan wirausaha tersebut bukan angka yang menggembirakan, karena apabila diamati secara detail ternyata para pedagang dan wirausaha tersebut didominasi oleh pedagang kecil yang hanya berpenghasilan rata-rata 600 ribu sampai satu juta rupiah perbulan. Kondisi yang demikain pemerintah daerah telah berusaha melakukan berbagai program pemerintah dalam rangka meningkatkan perekonomian masyarakat dilakukan antara lain melalui Program Raskin (beras miskin), Betonisasi jalan lingkungan, dan RTLH (Rumah Tidak Layak Huni), namun karena desa Leuwiliang memiliki luas 297.000.000 ha, dengan jumlah penduduk 12.887 orang dengan jumlah Kepala Keluarga sebanyak 3.196 KK dan juga diketahui bahwa sebanyak $25 \%$ belum memiliki pekerjaan maka program pemerintah tersebut sulit menjangkakau kebutuhan secara menyeluruh masyarakat Leuwiliang.

Tingginya angka pengangguran di desa Leuwiliang terjadi karena latar belakang pendidikan mereka yang sangat rendah sehingga pengetahuan mereka tentang teknologi terbatas, modal usaha terbatas pula dan apalagi menjadi tenaga pemasaran produk juga tidak mampu, masyarakat demikian merupakan masyarakat nonproduktif yang membebani desa tersebut. Di dalam membantu masyarakat non-produktif ini dan juga membantu program pemerintah daerah maka masyarakat kelompok ini akan dijadikan sebagai mitra untuk diberikan keterampilan, agar menjadi mandiri dan produktif. Ketrampilan dalam hal ini adalah ketrampilan pembuatan, pengemasan dan pemasaran tawas yang menggunakan bahan baku berupa kaleng bekas minuman yang banyak terdapat di sekitar Leuwiliang, sehingga diharapkan masyarakat dapat menjadi masyarakat yang produktif sehingga dapat meningkatkan kesejahteraan ekonomi keluarga.

Sisi lain dalam menjalankan program ini maka perlu tempat yang dapat dipakai sebagai lokasi pembuatan tawas, oleh karena itu abdimas kali ini menggandeng Yayasan Pendidikan Islam Saefulloh Assa'diyyah (YAPISA) untuk tempat produksi dan sebagai sentral aktifitas. YAPISA merupakan lembaga pendidikan yang berdiri tahun 2012 dan lembaga ini sedang berkembang dan sangat memperhatikan anak yatim. 
Berdasarkan hasil observasi karena jumlah murid yang terdaftar di sekolah tersebut masih sangat sedikit, maka lembaga ini layak dijadikan mitra.

Alternatif tersebut merupakan program dari Program Studi Kimia FMIPA UNPAK untuk memberikan alternatif keterampilan agar mendapatkan nilai tambah dengan membuat tawas dari bahan baku limbah kaleng bekas minuman. Program ini didanai DIKTI yang diharapkan dapat memiliki keuntungan langsung yakni : (1) Pengolahan kaleng bekas ini dapat mengurangi limbah anorganik yang sukar terurai oleh mikroorganisme dalam tanah. (2) Mengatasi masalah penduduk yang belum memiliki pekerjaan sehingga menjadi pengusaha tawas. Dari permasalahan yang ada didapat satu solusi yaitu dapat meningkatkan kesejahteraan melalui keterlibatan LPPM Universitas Pakuan.

\section{MATERI DAN METODE}

\section{Materi}

Bahan dasar pembuatan tawas pada program ini berasal dari limbah kaleng bekas minuman ringan (soft drink), bahan lain yang dipakai adalah amplas, gunting kaleng, $\mathrm{KOH}$ $10 \%, \mathrm{H}_{2} \mathrm{SO}_{4} 6 \mathrm{M}$, air, etanol, kertas saring, es batu (freezer), dan lain lain. Bahan bahan untuk penyuluhan adalah kertas HVS, kertas manila, ballpoint, spidol white board, snack dan makanan, aqua, sedangkan sarana dan prasarana yang diperlukan adalah LCD, layar, tempat, dan penyuluhan.

\section{Metode}

Berdasarkan masalah prioritas yang telah disepakati maka terdapat beberapa pendekatan metoda yang ditawarkan sebagai solusi, yaitu memberikan pelatihan pembuatan tawas dari kaleng bekas minuman untuk skala industri rumah tangga secara detail, kontinyu dan tuntas sampai dihasilkan produk dengan kualitas yang baik. Pada tahap awal dilakukan pembuatan Tawas di Laboratorium Kimia: Bahan dasar pembuatan tawas pada program ini berasal dari limbah kaleng bekas minuman ringan (soft drink). Pertama kaleng-kaleng bekas dibersihkan dengan menggunakan amplas untuk menghilangkan warna dan lapisan plastiknya. Kaleng bekas yang sudah dibersihkan kemudian digunting menjadi bagian yang kecil. Potongan-potongan kaleng bekas kemudian ditambahkan $\mathrm{KOH}$ $10 \%$ sambil dipanaskan di atas hotplate. Proses pemanasan dihentikan sampai gelembung-gelembung gas hilang. Larutan tersebut disaring lalu didinginkan. Selanjutnya filtrat ditambahkan $\mathrm{H}_{2} \mathrm{SO}_{4} 6 \mathrm{M}$ sambil diaduk dan dipanaskan diatas hotplate (Agung, 2015). Setelah itu dilakukan penyaringan. Filtrat didinginkan di dalam Freezer $2-8^{\circ} \mathrm{C}$. Kristal tawas yang terbentuk dipisahkan dan dicuci dengan etanol 50\%. Tahap akhir endapan dikeringkan dan tawas siap untuk digunakan.

Metode pelatihan pembuatan tawas dari limbah kaleng bekas minuman ini akan dilakukan melalui beberapa tahapan yaitu :

a. Pemberian materi untuk menambah wawasan mengenai tawas dan manfaatnya dalam kehidupan sehari-hari dan di industri. Dalam pelatihan ini juga diberikan wawasan tentang cara pembuatan tawas dari kaleng bekas minuman. Tahap awal ini akan dilakukan selama kurang lebih satu bulan pertama,

b. Pelatihan membuat tawas dari limbah kaleng bekas minuman. Pada pelatihan ini merupakan praktek membuat tawas dimulai cara membersihkan dan memotong kaleng kaleng bekas minuman agar proses pembentukan tawas berjalan sempurna sehingga dihasilkan tawas yang baik.

c. Evaluasi secara menyeluruh keberhasilan membuat tawas uji coba, tawas sintesi dalam menjernihkan air. 


\section{HASIL DAN PEMBAHASAN}

\section{Hasil}

Sebelum melakukan penyuluhan Pembuatan tawas dari kaleng bekas minuman maka Tim IbM melakukan sosialisasi program dalam rangka membuat komitmen antara Tim Pengabdian Pada Masyarakat bersama Masyarakat RW 10 Desa Leuwiliang. Pada Gambar 1, Gambar 2, Gambar 3, Gambar 4, Gambar 5, Gambar 6, Gambar 7, Gambar 8, Gambar 9, dan Gambar 10 diperlihatkan foto pada saat sosialisasi program.

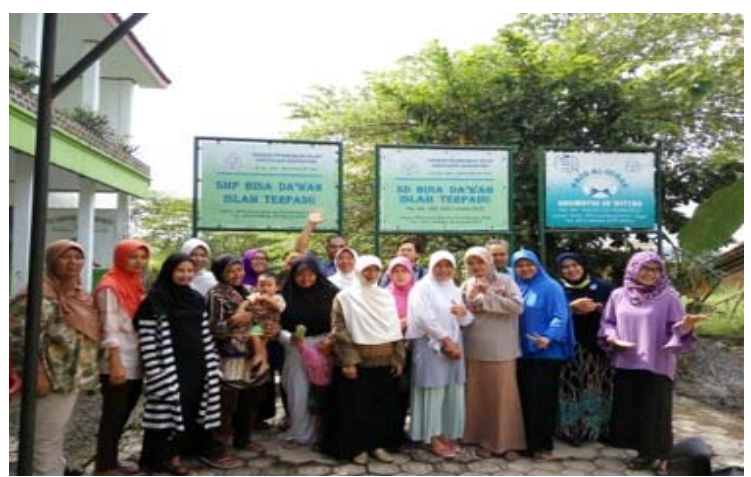

Gambar 1 Foto saat sosialisasi program dalam rangka membuat komitmen dari tim pengabdian pada masyarakat bersama masyarakat RW 10 Desa Leuwiliang

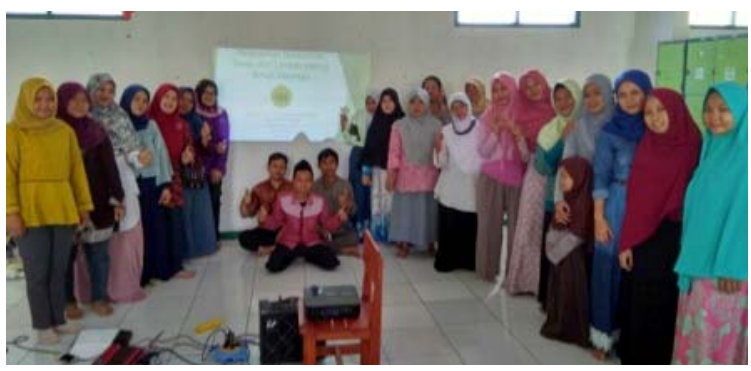

Gambar 2 Foto tim pelaksana pengabdian bersama mitra selesai penyuluhan

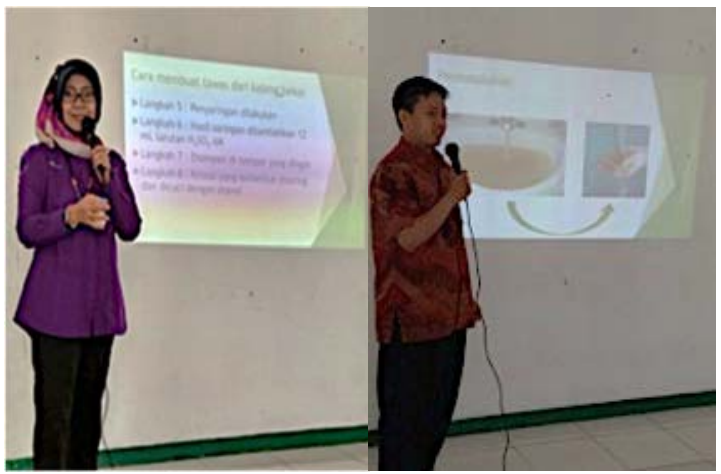

Gambar 3 Tim pelaksana pengabdian sedang memberikan penyuluhan pembuatan tawas
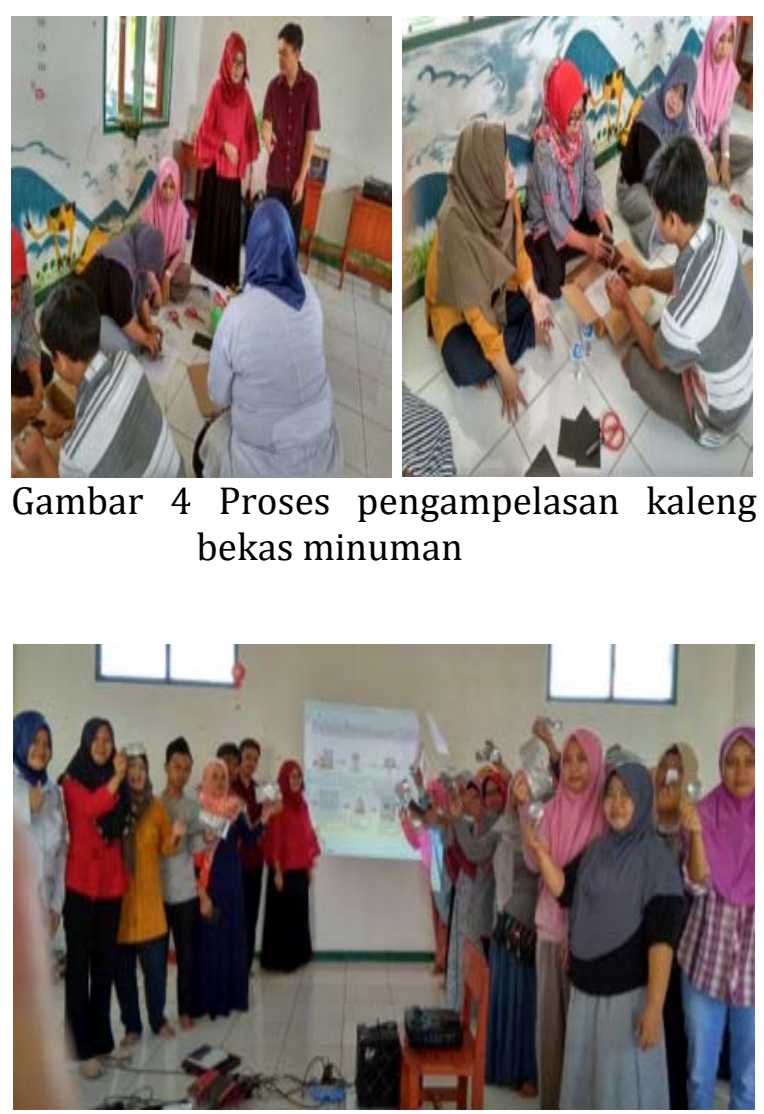

Gambar 5 Foto tim pelaksana bersama mitra setelah selesai proses pengampelasan 


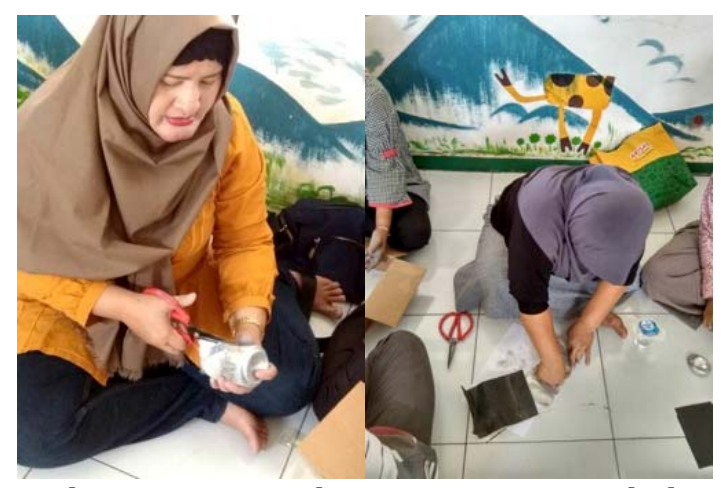

Gambar 6 Mitra sedang menggunting kaleng bekas minuman

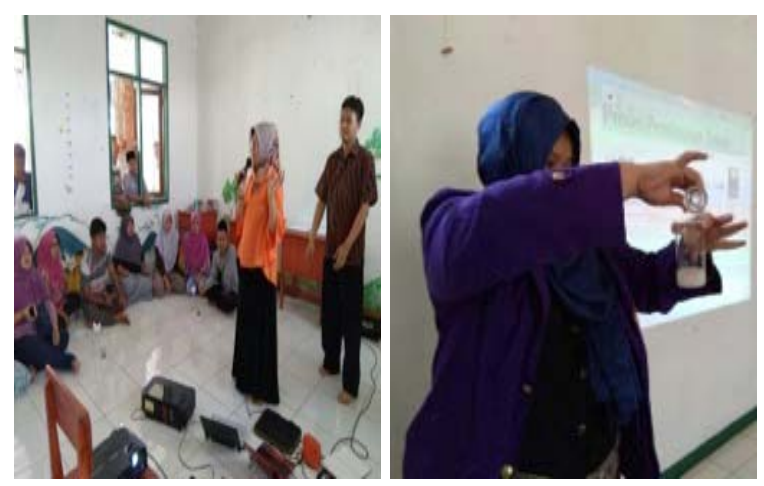

Gambar 7 Mitra melakukan proses reaksi antara potongan kelang bekas dengan $\mathrm{KOH}$ dan $\mathrm{H}_{2} \mathrm{SO}_{4}$ dipandu oleh tim pelaksana IbM

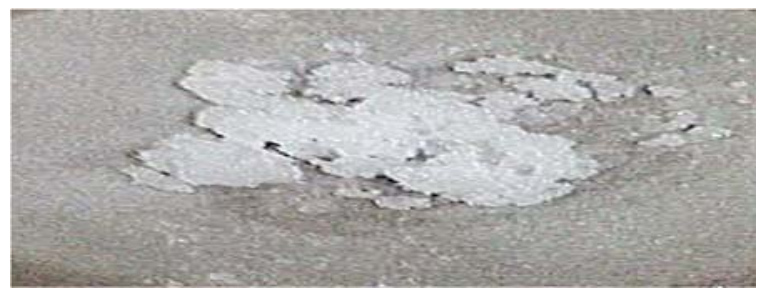

(a)

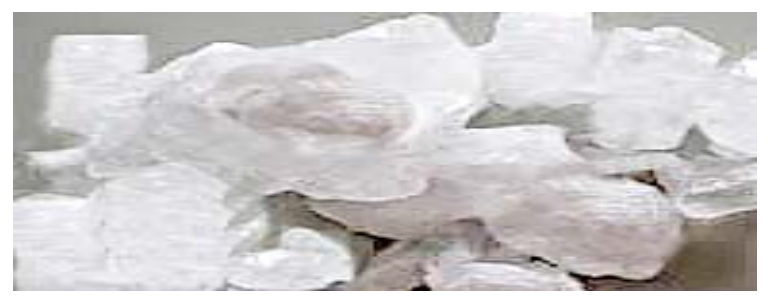

(b)

Gambar 8 Hasil uji coba prosedur pembuatan tawas (a) kristal tawas belum sempurna (b) kristal sempurna

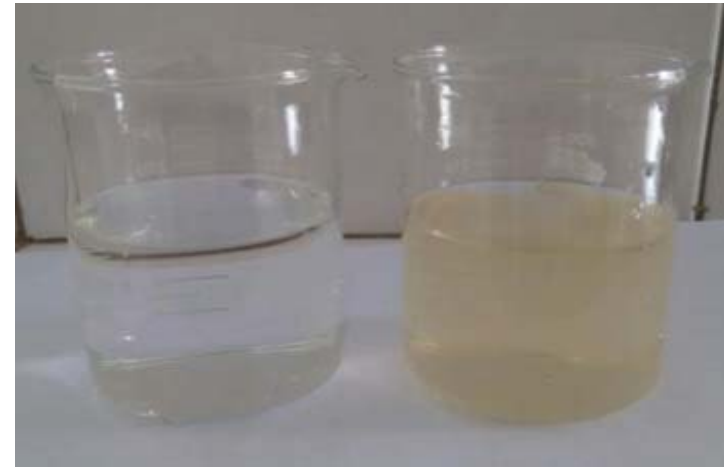

(a)

(b)

Gambar 9 Hasil uji penggunaan tawas diperlihatkan dari perbandingan warna kondisi air (a) setelah diberi tawas dan (b) sebelum diberi tawas

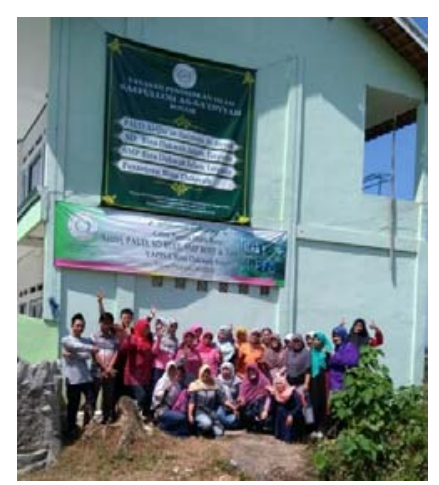

Gambar 10 Foto tim pelaksana pengabdian bersama mitra

\section{Pembahasan}

Kegiatan PKM Pemberdayaan Masyarakat Non Produktif Melalui Keterampilan Pembuatan Tawas dari Limbah Kaleng Bekas Minuman telah dilakukan melalui berbagai tahapan, tahap pertama adalah Sosialisasi Program Kemitraan Masyarakat (PKM) Pemberdayaan Masyarakat Non Produktif Melalui Keterampilan Pembuatan Tawas dari Limbah Kaleng Bekas.

Program ini mulai dilakukan di lokasi kegiatan pada tanggal 12 April 2016 sebagai upaya untuk menyampaikan informasi adanya program kegiatan tersebut di atas serta manfaatnya bagi masyarakat. Di dalam program ini sekaligus merupakan ajang kesepakatan dan komitmen mitra masyarakat untuk mengikuti kegiatan pelatihan secara serius dan tuntas nantinya. 
Sosialisasi ini dihadiri oleh 21 orang warga masyarakat Leuwiliang, tidak hanya laki-laki tetapi ibu-ibu rumah tangga yang non produktif pun yang siap mengikuti kegiatan ini pada tahap-tahap selanjutnya. Sambutan masyarakat mitra tersebut sangat tertarik dan antusias dengan adanya gagasan kegiatan tersebut, meskipun mereka sangat minim dalam ilmu pengetahuan dan teknologi yang ia miliki, tetapi antusias yang tinggi merupakan modal yang sangat penting. Sesungguhnya masyarakat Leuwiliang sangat menantikan kegiatankegiatan seperti ini, yang secara sadar mereka sangat mengetahui akan manfaat bagi mereka sendiri untuk menambah ilmu pengetahuan dan keterampilan yang dapat mereka manfaatkan untuk meningkatkan kesejahteraan mereka. Begitulah dalam kasus ini maka Tim kami harus dapat memformulasikan gagasan yang ada agar menjadi teknologi generik yang dapat difahami masyarakat awam kimia agar dapat bermanfaat pada mereka. Berikut keceriaan ibu-ibu dan bapak-bapak yang tergambar dalam gambar 1 dan gambar 2 dapat dilihat foto pada saat sosialisasi kegiatan oleh Tim Pengabdian Pada Masayarakat yang dihadiri oleh masyarakat non produktif yang sebagian besar ibu-ibu rumah tangga di Desa Leuwiliang, Kecamatan Leuwiliang, Kabupaten Bogor.

Kedua, penyuluhan tata cara pembuatan tawas dengan menggunakan bahan baku kaleng bekas minuman, program ini akhirnya dilakukan setelah melalui proses pengusulan gagasan di atas lewat DPRM untuk pendanaan tahun 2017. Selanjutnya setelah dilakukan uji coba di laboratorium Kimia FMIPA-Unpak beberapa kali maka tata cara pembuatan tawas dari kaleng bekas minuman diputuskan telah sesuai dengan skenario. Hasilnya setiap $1 \mathrm{~g}$ kaleng bekas minuman diperoleh 18,9 gram tawas.

Setelah dilakukan uji coba pembutan tawas dari kaleng bekas minuman beberapa kali di dalam laboratorium akhirnya didapatkan resep yang paling baik dari hasil kristal yang didapat, hasil kirstal tersebut menandakan bahwa kristal hasil menggambarkan kristal tawas yang cukup sempurna. Didasarkan pada data-data prosedur yang dilakukan baik komposisi maupun parameter temperatur dan pengadukan serta parameter lain-lainnya maka dapat dipilih dan dipastikan prosedur mana yang akan diberikan pada pelatihan pembuatan tawas dari kaleng bekas minuman.

Hasil prosedur pembuatan di atas akhirnya dipakai sebagai bahan yang diajarkan dalam pelatihan yang dilakukan pada tanggal 10 Juli 2017 sampai selesai. Pada pelaksanaannya, penyuluhan tata cara pembuatan tawas menggunakan bahan baku limbah kaleng bekas minuman ini dihadiri oleh 23 orang. Jumlah ini lebih banyak daripada pada saat sosialisasi program gambar 2. Hal ini menunjukkan bahwa telah terjadi penyebaran informasi antara masyarakat mengenai program ini yang kemudian menarik perhatian sehingga ingin ikut terlibat dalam program ini. Namun kebanyakan pesertanya adalah ibu-ibu, seperti yang terlihat dalam gambar 2 berikut. Berdasarkan pengamatan, selama proses penyuluhan, terlihat para peserta sangat antusias memperhatikan penjelasanpenjelasan bagaimana cara membuat tawas dari bahan baku kaleng bekas minuman. Hal ini kemungkinan karena penyuluhan ini merupakan hal yang baru bagi peserta dan kemungkinan lain karena manfaat bagi peserta yang tinggi.

\section{Proses Pembuatan Tawas Dengan Menggunakan Bahan Baku Limbah Kaleng Bekas Minuman (Bagian 1)}

Pelatihan pembuatan tawas dengan menggunakan bahan baku limbah kaleng bekas minuman bagian 1 meliputi pengenalan bahan berbahaya, dan pengenalan peralatan yang dipakai. Di dalam proses pembuatan tawas ini terdapat beberapa bahan yang berbahaya, pengenalan bahan berbahaya ini mutlak penting oleh karena itu dilakukan penyuluhan terlebih dahulu agar mengurangi dapat terjadinya kecelakaan dalam pelatihan pembuatan tawas. 
Pemberian penyuluhan tatacara penanganan zat-zat tersebut agar masyarakat atau peserta dapat mengetahui dengan jelas bagaimana penanganan zat-zat yang dipakai dalam proses tersebut. Sehingga diharapkan proses pembuatan tawas dapat berjalan lancar. Selanjutnya pengenalan dan cara kerja peralatan yang digunakan untuk proses sintesis satu persatu, agar saat proses pembuatan sudah dikenali dengan baik cara kerja peralatan tersebut yang terkait dengan proses tiap-tiap langkah gambar 3 .

\section{Proses Pembuatan Tawas dengan Menggunakan Bahan Baku Limbah Kaleng Bekas Minuman (Bagian 2)}

Proses pembersihan kaleng bekas minuman dengan menggunakan amplas ini merupakan hal sangat penting untuk mengurangi kontaminasi bahan yang akan dipakai sebagai bahan baku pembuatan tawas. Selain pengampelasan kaleng tersebut yang tidak kalah pentingnya adalah bagaimana teknik penyortiran kaling yang berkadar aluminium tinggi atau yang berbahan timah tinggi. Didalam pemilihan kaleng ini menginformasikan dan melatih pemilihan kualitas bahan baku, hal ini sangat penting karena saat pemilihan ini pada akhirnya merupakan indikator kuantitas tawas yang didapat dari proses pembuatan tersebut. Sehingga atusias yang ada cukup tinggi mengingat kegagalan ini merupakan turunnya kuantitas tawas yang dibikin dan akan berakibat pada turunnya pendapatan mereka. Berikut ini gambar 4 dan 5 adalah foto-foto dokumentasi pada saat pelatihan pembuatan tawas bagian 1, semua peserta berusaha ingin tahu bagaimana kualitas kaleng bekas minuman yang kerkualitas baik untuk bahan tawas..

Proses lain selain pengamplasan dan penyortiran adalah proses pemotongan kaleng bekas minuman dengan menggunakan gunting kaleng sampai ukuran yang sangat kecil kira-kira $(0,5 \times 0,5) \mathrm{cm}$. Pelatihan yang dilaksanakan pada tanggal 02 Agustus 2017 ini juga dihadiri oleh 23 orang. Peserta yang hadir pada pelatihan ini juga sama dengan yang hadir pada pelatihan pengampelasan limbah kaleng bekas minuman. Hal ini menunjukkan konsistensi mereka dalam mengikuti pelatihan karena mereka sangat berharap ada perbedaan pengetahuan yang bisa dimiliki yang dapat diharapkan menjadai harapan baru. Berikut gambar 6 menunjukkan foto-foto dokumentasi pada saat pelatihan pembuatan tawas bagian 2 .

\section{Proses Pembuatan Tawas dengan Menggunakan Bahan Baku Limbah Kaleng Bekas Minuman (Bagian 3)}

Pada tahap ini merupakan pelatihan pembuatan tawas dengan mereaksikan bahan baku limbah kaleng bekas minuman bagian 3 meliputi proses mereaksikan potongan kaleng dengan Kalium Hidroksida $(\mathrm{KOH})$ dan Asam Sulfat $\left(\mathrm{H}_{2} \mathrm{SO}_{4}\right)$. Pelatihan yang dilaksanakan pada tanggal 09 Agustus 2017 ini juga dihadiri oleh 23 orang. Pada saat pelatihan mereka terlihat masih takut dan ragu-ragu dalam menggunakan bahan kimia tersebut. Namun dengan adanya bantuan dari laboran akhirnya proses ini pun berhasil dilakukan. Berikut ini adalah fotofoto dokumentasi pada saat pelatihan pembuatan tawas bagian 3 sedang hasil tawas yang ada pada gambar 7 dan hasil tawas yang di dapat pada gambar 8 .

Demikianlah kegiatan Program Kemitraan Masyarakat (PKM) yang telah kami lakukan dalam kegiatan Pemberdayaan Masyarakat Non Produktif Melalui Keterampilan Pembuatan Tawas dengan menggunakan bahan baku limbah kaleng bekas minuman. Beberapa hal yang belum kami laksanakan yaitu : Aplikasi penggunaan Tawas untuk menjernihkan Air, Pengemasan Tawas, Pemberian Label dan Pendampingan Pemasaran Tawas yang telah dihasilkan sehingga dapat meningkatkan kesejahteraaan masyarakat tersebut.

Kegiatan Program Kemitraan Masyarakat (PKM) mulai dari sosialisasi program sosialisasi sampai kepada pelatihan pembuatan tawas, teknik pengemasan dan pemasaran. Kerjasama yang baik terjadi antara tim pelaksana dengan mitra sehingga kegiatan demi kegiatan dapat berjalan 
dengan baik. Hal ini disebabkan karena mereka memang memiliki masalah di bidang air bersih. Wilayah mitra dulunya adalah daerah persawahan, sehingga ketika membuat sumur pasti air yang dihasilkannya keruh. Berikut sebagai gambaran kondisi air di wilayah mitra dan hasil setelah di beriak tawas terlahat pada gambar 9 .

Pada akhirnya Pelatihan dan penyuluhan dalam abdimas pembuatas tawas dari kaleng bekas minuman berakhir sebelum mengakhiri kursus tersebut maka beberapa peserta mengabadikan program penting tersebut dengan melakukan foto bersama yang terlihat pada gambar 10 .

\section{KESIMPULAN DAN IMPLIKASI}

\section{Kesimpulan}

Berdasarkan Program Kemitraan Masyarakat yang telah dilakukan dapat disimpulkan bahwa :

a. Masyarakat non produktif terbuka wawasannya mengenai peluang usaha tawas.

b. Masyarakat non produktif mempunyai keterampilan membuat tawas dari bahan baku limbah kaleng bekas minuman.

c. Masyarakat non produktif dapat memanfaatkan limbah kaleng bekas menjadi tawas yang bisa digunakan untuk menjernihkan air.

d. Tawas kaleng bekas terbukti efektif sebagai koagulan walau dosis pemakaian lebih banyak. Tawas kaleng bekas mampu menurunkan turbuditi hingga mendekati nol

\section{Implikasi}

Untuk pelaksanaan Program Kemitraan Masyarakat selanjutnya implikasi:

a. Produksi tawas diperbanyak sehingga dapat menjangkau pasar yang lebih luas.

b. Masyarakat diberikan pengetahuan cara pengemasan produk tawas dan membuat label dari produk tawas yang dihasilkan.

\section{UCAPAN TERIMA KASIH}

Program Pengabdian Pada Masyarakat ini didukung secara finansial oleh Direktorat Riset dan Pengabdian Masyarakat, Direktorat Jenderal Penguatan Riset dan Pengembangan, Kementerian Riset, Teknologi dan Pendidikan Tinggi, sesuai dengan Surat Perjanjian Penugasan Pelaksanaan Program Pengabdian Masyarakat, Perguruan Tinggi Swasta, Di Lingkungan Kopertis Wilayah IV, Tahun Anggaran 2017, Nomor : 1602/K4/KM/2017

\section{DAFTAR PUSTAKA}

Agung, 2013. Sintesis Tawas Kalium Aluminium Sulfat [KAl(SO4)2.12H2O] dari Kaleng Bekas Minuman Sebagai Zat Penjernih Air. Skripsi. Jurusan Kimia FMIPA. Unpak.

Iryani, Ani., Soraya, Dea dan Mulyati, Ade H., 2015, " WASTEWATER TREATMENT AT PT. X BY ACTIVE SLUDGE ( Pengolahan Limbah Cair PT. X Secara Lumpur Aktif)", _Jurnal Science_, Volume, Issue/nomor, halaman

Disti, SP. 2016. Pembuatan Koagulan Penjernih Air Dari Limbah Kaleng Minuman Ringan dan Aluminium Foil Kemasan. Skripsi, Jurusan Kimia FMIPA. Unpak.

Jaswin, M. 2008. Packaging materials and its application. Jakarta: Indonesian Packaging Federation.

Kotler, P. 1997. Manajemen Pemasaran. Jilid 1 dan 2. Jakarta: Salemba Empat.

Laporan Kegiatan Tahun 2015 Desa Leuwiliang Kecamatan Leuwiliang Kabupaten Bogor

Pemerintah Desa Leuwiliang. Profil Umum dan Demografi Desa Leuwiliang. Tersedia online http://kecamatanleuwiliang.bogorkab.go .id/index.php/multisite/detail_desa/269

Purnamasari R.D, Iryani, A., Aminingsih T., 2016, Pemanfaatan Kacang Babi (Vicia faba) dan Biji Asam Jawa (Tamarindus indica L) Sebagai Koagulan Alami Pada Proses Perbaikan Kualitas Air, Article. 
Qardhul Hasan: Media Pengabdian kepada Masyarakat p-ISSN 2442-3726 e-ISSN 2250-1143 